\title{
Laboratory Diagnosis of Nosocomial Bacterial Infections Using Standard Methods
}

Saeideh Sadat Shobeiri (BSc)

Department of Immunology,

Mazandaran University of Medical

Sciences, Sari, Iran

Saeid Abediankenari (Phd)

Department of Immunology,

Mazandaran University of Medical

Sciences, Sari, Iran

Mohtaram Nasrollahi (PhD)

Department of Microbiology,

Mazandaran University of Medical

Sciences, Sari, Iran

Mohammad Khademlou (PhD)

Department of Social Medicine,

Mazandaran University of Medical

Sciences, Sari, Iran

Maryam Sarabijamab (MD)

General Physician, Mazandaran

University of Medical Sciences, Sari,

Iran

Corresponding author: Saeed

Abedian

Email: abedianlab@yahoo.co.uk

Tel: +989121985667

Address: Department of Immunology,

Mazandaran University of Medical

Sciences, Sari, Iran

Received : 06 Jul 2014

Revised: 20 Oct 2014

Accepted: 27 Oct 2014

\section{ABSTRACT}

Background and Objective: Implementation of standard methods for accurate detection of bacteria, correct antibiotic susceptibility testing and effective treatment of bacterial infections play important roles in development of public health and prevention of drug resistance. This study aimed to detect bacteria using standard methods and compare the results with the results obtained in teaching hospitals' laboratories.

Methods: Positive culture plates containing bacteria isolated from patients in hospital laboratories in city of Sari were transferred to microbiology laboratory of Faculty of Medicine at Mazandaran University of Medical Sciences, after determining the genus and species of bacteria and antibiotic susceptibility testing of the isolates. The samples were re-examined based on standard protocols, and antibiotic susceptibility testing was carried out using the Kirby-Bauer method.

Results: 0f 101 patients, $20 \%$ of bacteria and 22.5\% of antibiotic sensitivity results reported by the hospital laboratories were incorrect. There was significant difference between the two study groups in terms of bacterial species detection and sensitivity to some drugs $(\mathrm{P}<0.05)$.

Conclusion: In the present study, lack of implementation of internal quality control programs in some hospital laboratories and lack of proper monitoring by regulatory authorities in different departments of the hospital have caused $20 \%$ false-detection results in hospital reports. Inconsistency in the results of laboratories, false antibiograms and subsequent false laboratory reports cause drug resistance in some patients. This indicates the necessity of continuous training in the field of Microbiology and implementation of standard protocols and methods for detection of bacterial species and antibiotic susceptibility testing.

Keywords: Culture, Drug Resistance, Antibiogram. 


\section{INTRODUCTION}

Bacterial infections are among the main causes of infectious disease, and morbidity and mortality in the world (1). Accurate diagnosis and proper identification of these factors lead to proper treatment of the disease and prevent loss of human and economic resources. In this regard, clinical laboratories in hospitals are of particular importance. Escherichia coli is a bacterial pathogen and main cause of urinary tract infection. Staphylococcus aureus and Pseudomonas aeruginosa are the main causes of wound infection and nosocomial infection, respectively. In this regard, having sufficient knowledge of microbiology and experience, using the latest scientific resources of microbiology and ultimately using the latest protocols provided by the World Health Organization (WHO) and reference laboratories in detection of genus and species of bacteria are of great importance. Accurate and standard detection of bacteria, correct antibiogram, and timely and effective treatment of diseases have important roles in the development of public health (2). Mismatch in the results of laboratories, incorrect antibiograms and false laboratory reports based on it, have caused many problems in the society (3).

In this regard, drug resistance is a health problem, which is caused by overuse and inappropriate prescription of drugs (4). Currently, drug resistance is considered a public health problem, which also has an important role in nosocomial infections (5-10). Obviously, correct diagnosis and timely treatment of bacterial infections reduce nosocomial infections and cost of treatment. Hence, this study aimed to evaluate bacterial cultures and antibiotic sensitivity tests in some hospital laboratories, and compare their results with the results of implementing the WHO and reference laboratories' standard protocols.

\section{MATERIALS AND METHODS}

Overall, 101 samples of positive bacterial cultures (including blood agar, Mueller Hinton, chocolate agar and blood culture plates) were collected from three hospital laboratories in Sari and then transferred to department of microbiology at Mazandaran University of Medical Sciences. The samples were passaged in specific and non-specific culture media. After 24 to 72 hours of incubation at $37{ }^{\circ} \mathrm{C}$ with and without $\mathrm{Co}_{2}$, microscopic slides were prepared from the samples and then Gram staining was performed. Based on the results of Gram staining, differential tests were performed according to the guidelines provided by the WHO and reference laboratories (11). After determining the genus and species and comparing them with the results of hospital laboratories, the antibiotic susceptibility testing was done using standard method of Kirby-Bauer and disk diffusion method. The diameter of inhibition zone was measured and the sensitivity or resistance of isolates was determined based on standard tables. Antibiotic sensitivity test was performed using the same antibiotic disks used in the hospital laboratories.

\section{RESULTS}

The results indicated the difference in the number and species of detected bacteria between the methods used by hospital laboratories and the reference method (Table 1). In addition, the results of antimicrobial susceptibility testing had significant difference $(\mathrm{P}<0.05)$ in sensitivity to some antibiotics such as gentamicin and ceftizoxim (Table 2).

The results of antibiotic susceptibility tests also showed differences in the results reported by the hospital laboratories and this study. In this study, the sensitivity of each isolate to antibiotics was compared with each other to identify the difference between the results of hospital laboratories and laboratory of Faculty of Medicine. The results reported by hospital laboratories and laboratory of Faculty of Medicine (table 3) showed a significant difference $(\mathrm{P}<0.05)$ for sensitivity of $S$. aureus to cephalothin, E.coli and $S$. aureus sensitivity to gentamicin, E. coli sensitivity to cefotaxime, E.coli and $S$. aureus sensitivity to nitrofurantoin, E. aerogenes sensitivity to cotrimoxazole and $S$. aureus sensitivity to vancomycin . 
Table 1-Comparison of the results of samples' culture in the hospital laboratories and laboratory of Faculty of Medicine

\begin{tabular}{|c|c|c|}
\hline $\begin{array}{c}\text { Faculty's } \\
\text { laboratory } \\
\text { (number of } \\
\text { cases) }\end{array}$ & $\begin{array}{c}\text { Hospitals } \\
\text { (number } \\
\text { of cases) }\end{array}$ & $\begin{array}{l}\text { Study group } \\
\text { Species }\end{array}$ \\
\hline 53 & 61 & E. coli \\
\hline 12 & 10 & S. aureus \\
\hline 7 & $\mathbf{0}$ & Enterobacter cloacae \\
\hline 3 & 1 & E. aerogenes \\
\hline 5 & 6 & Pseudomonas spp. \\
\hline 5 & 7 & Enterobacterspp. \\
\hline $\mathbf{0}$ & 2 & Staphylococcus spp. \\
\hline 3 & 3 & Coagulase-negative staphylococci \\
\hline 1 & $\mathbf{0}$ & S. epidermidis \\
\hline $\mathbf{0}$ & 3 & S. saprophyticus \\
\hline 1 & $\mathbf{1}$ & $P$. aeruginosa \\
\hline 3 & $\mathbf{0}$ & Burkholderia cepacia \\
\hline $\mathbf{0}$ & 3 & Proteus spp. \\
\hline 2 & $\mathbf{0}$ & P. mirabilis \\
\hline 1 & $\mathbf{0}$ & Citrobacter Diversus \\
\hline 1 & $\mathbf{0}$ & C. freundii \\
\hline 1 & $\mathbf{0}$ & Serratia marcescens \\
\hline 3 & 1 & Klebsiella spp. \\
\hline $\mathbf{0}$ & 2 & Gram-negative bacilli \\
\hline
\end{tabular}

Table 2 -Comparison of the results of antibiotic sensitivity testing reported by the hospitals and laboratory of Faculty of Medicine

\begin{tabular}{|c|c|c|c|c|c|}
\hline \multirow[b]{2}{*}{ P-value } & \multicolumn{2}{|c|}{ Laboratory of Faculty of Medicine } & \multicolumn{2}{|c|}{ Hospital laboratories } & \multirow{2}{*}{$\begin{array}{l}\text { Group } \\
\text { Antibiotic }\end{array}$} \\
\hline & $\begin{array}{c}\text { Resistant } \\
\text { Number of cases } \\
\text { (percentage) }\end{array}$ & $\begin{array}{c}\text { Sensitive } \\
\text { Number of cases } \\
\text { (percentage) }\end{array}$ & $\begin{array}{c}\text { Resistant } \\
\text { Number of cases } \\
\text { (percentage) }\end{array}$ & $\begin{array}{c}\text { Sensitive } \\
\text { Number of cases } \\
\text { (percentage) }\end{array}$ & \\
\hline $\mathbf{P}>\mathbf{0 . 0 5}$ & $(80 \%) 72$ & $(20 \%) 18$ & $(86.7 \%) 52$ & $(13.3 \%) 8$ & Cephalothin \\
\hline$P<0.05$ & $(37.5 \%) 36$ & $(62.5 \%) 60$ & $(69.1 \%) 56$ & $(30.9 \%) 25$ & Gentamicin \\
\hline$P<0.05$ & $(45.5 \%) 40$ & $(54.5 \%) 48$ & $(72.9 \%) 51$ & $(27.1 \%) 19$ & Ceftizoxime \\
\hline $\mathbf{p}>\mathbf{0 . 0 5}$ & $(37.5 \%) 36$ & $(62.5 \%) 60$ & $(51.3 \%) 41$ & $(48.8 \%) 39$ & Nitrofurantoin \\
\hline $\mathbf{p}>\mathbf{0 . 0 5}$ & $(55.7 \%) 54$ & $(44.3 \%) 43$ & $(68.4 \%) 65$ & $(31.6 \%) 30$ & Cotrimoxazole \\
\hline $\mathrm{p}>\mathbf{0 . 0 5}$ & $(52.1 \%) 50$ & $(47.9 \%) 46$ & $(56.3 \%) 49$ & $(43.7 \%) 38$ & Ciprofloxacin \\
\hline $\mathbf{p}>\mathbf{0 . 0 5}$ & $(37.5 \%) 6$ & $(62.5 \%) 10$ & $(37.5 \%) 3$ & $(62.5 \%) 5$ & Norfloxacin \\
\hline p $>0.05$ & $(67.9 \%) 53$ & $(32.1 \%) 25$ & $(74.2 \%) 46$ & $(25.8 \%) 16$ & Nalidixic acid \\
\hline$P<0.05$ & $(26.7 \%) 4$ & $(73.3 \%) 11$ & $(76.9 \%) 10$ & (23.1) 3 & Vancomycin \\
\hline
\end{tabular}

Table 3- Comparison of sensitivity of bacteria to gentamicin and cotrimoxazole

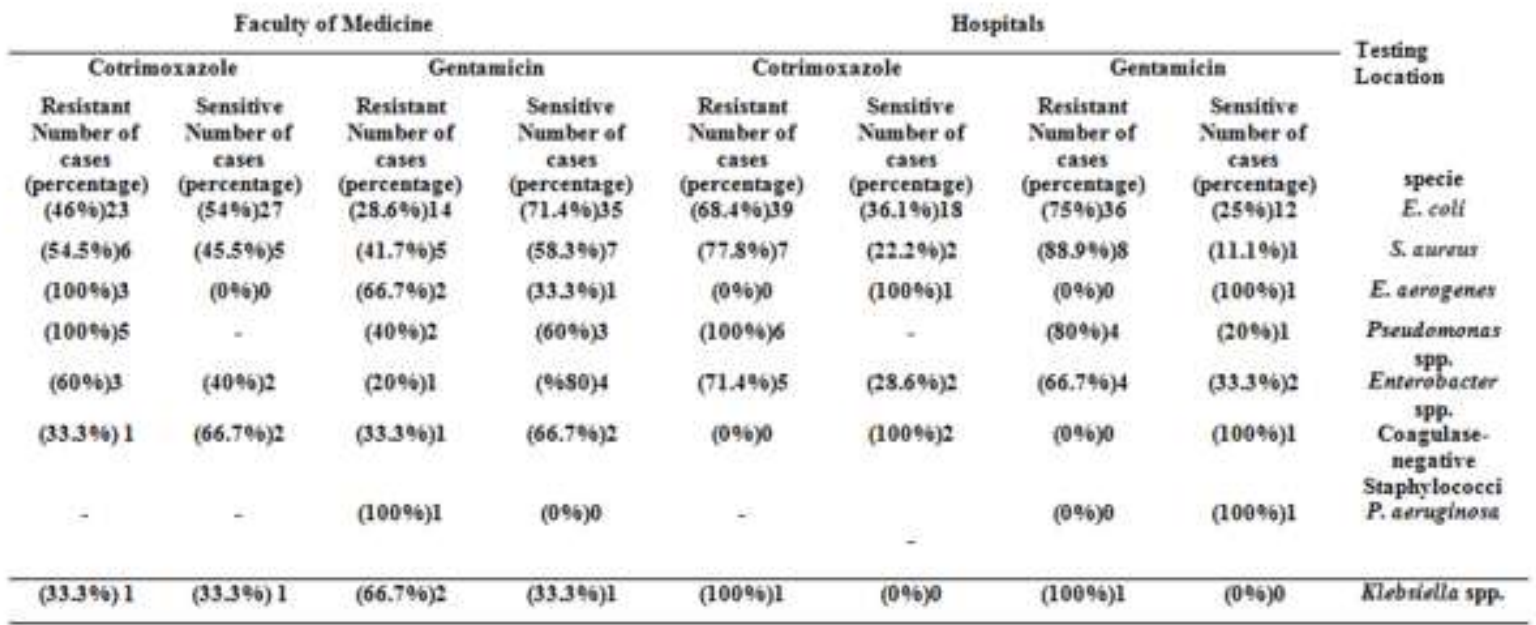




\section{DISCUSSION}

Bacterial infections are among the most common causes of death in humans. Thus, timely diagnosis of causes of infections and determining their susceptibility to antibiotics can be the effective steps toward promoting patient's health and reducing mortality. The present study was designed to detect bacteria and determine their susceptibility to antibiotics using standard methods. Overall, $80 \%$ and $78.5 \%$ similarity was observed between the results of the culture and antibiotic susceptibility testing between the two groups, respectively. According to some inconsistent reports obtained from the hospital laboratories and laboratory of Faculty of Medicine, there were also differences in the number and species of bacteria. In the results of Faculty of Medicine laboratory, species such as $P$. mirablis, $C$. diversus, $C$. freundii and $S$. marcescens were identified, while these species of bacteria were not reported by the hospital laboratories and might have been falsely reported as other species. These differences may be due to not using IMViC differential media and specific tests for detection of bacteria in the hospital laboratories, while the use of differential media and other specific tests in the laboratory of Faculty of Medicine led to identification of more species. The difference in the cases of $S$. aureus reported by the hospital and Faculty of Medicine indicates that unlike the Faculty of Medicine laboratory, coagulase, DNase and mannitol fermentation tests were not used in the hospital labs for identification of bacteria.the difference in the number of cultivated Klebsiella spp. also indicates the lack of using Simmons' citrate agar, VogesProskauer test, mannitol salt agar and other differential media for identification of these bacteria in hospitals. In addition, $S$. saprophyticus has not been reported by the laboratory of Faculty of Medicine, while hospital laboratories have reported three cases of this specie. Moreover, S. epidermis was not reported by the hospital laboratory, while the laboratory of Faculty of Medicine reported one case of this bacterium. This may be due to not testing the sensitivity to novobiocin for differentiation of $S$. epidermidis from $S$. saprophyticus. For identification of Streptococci in the laboratory of Faculty of Medicine, sensitivity to bacitracin was assessed for identification of group a betahemolytic streptococci and optochin susceptibility testing was performed to differentiate $S$. pneumoniae from alphahemolytic streptococci. Based on the findings of the present study, the results of susceptibility testing were also inconsistent. Given that the same antibiotic disks (same manufacturer) were used in both groups, failure to carry out the Kirby-Bauer method properly caused a significant difference in some of the results. Of the nine antibiotics used, significant differences were observed in the sensitivity of bacteria to gentamicin, ceftizoxime and vancomycin between the two groups. In this study, a separate comparison of the sensitivity of each bacterium to the antibiotics was made. This comparison showed significant difference between $S$. aureus sensitivity to cephalothin, $E$. coli and $S$. aureus sensitivity to gentamicin, $E$. coli sensitivity to ceftizoxime, E. coli and S. aureus sensitivity to nitrofurantoin, $E$. aerogenes sensitivity to cotrimoxazole and $S$. aureus sensitivity to vancomycin in the results reported by the hospital laboratories and laboratory of Faculty of Medicine. In study of Karlowskey et al., coagulase-negative $S$. aureus, $S$. aureus, Enterococcus faecalis, Klebsiella and E. coli were the most common isolated bacteria (12). Study of Hsueh et al. in Taiwan showed that Candida, P. aeruginosa and E. coli are the main causes of nosocomial infections and septicemia, respectively (13). Consistent with the results of other studies, E. coli and $S$. aureus were the most frequently isolated bacteria in the present study. Karlowskey et al. reported that the highest sensitivity of common bacteria isolates was to ceftriaxone (12), while the highest level of sensitivity among bacteria in the present study was to norfloxacin. Hsueh et al. reported increased resistance to cefotaxime among enterobacteria, especially $K$. pneumoniae, while the highest level of antibiotic resistance was observed in Klebsiella and Pseudomonas against ceftizoxime. Bilgin Arda et al. conducted a study on 1000 patients in Turkey and showed increased resistance of $S$. aureus to antibiotics such as gentamicin, methicillin and penicillin, and increased resistance of Klebsiella to ciprofloxacin and cefotaxime from 2002 to 2003 (14). 


\section{CONCLUSION}

The appropriate use and proper prescription of antibiotics are among the most important ways to prevent drug resistance and reduce healthcare costs. Based on the results of this study, it is recommended to implement standard diagnostic methods in hospitals according to protocols provided by the WHO and reference laboratories, and replace KirbyBauer antibiotic testing with traditional susceptibility testing methods for a more complete and accurate identification of

\section{REFERENCES}

1. Finland M, Jones WF, Barens M. Occurrence of serious bacterial infections since introduction of antibacterial agents. J Am Med Asso. 1959; 170: 218897. PMID:13822924.

2. Plowman R, Graves N, Girrifin M, Roberts J, Swan B, Taylor I. The Socio-economic burden of hospital acquired infection. Euro Surveill. 2000; 5(4): 49-50. PMID:12631865.

3. Holmberg SD, Solomon SL, Blake PA. Health and economic impacts of antimicrobial resistance. Rev Infect Dis. 1987; 9(6): 1065-78.

4. Kollef M. Inadequate antimicrobial treatment: an important determinant of outcome for hospitalized patients. Clin infect dis. 2000; 31; 131-138. PMID: 11017862.

5. Cardo D. National Nosocomial Infections Surveillance (NNIS) System Report, data summary from January 1992 through June 2004, issued October 2004.National Nosocomial Infections Surveillance System.Am J Infect Control. 2004; 32(8): 470-85.

6. Emori TG, Gaynes RP. An overview of nosocomial infections, including the role of the microbiology laboratory .Clin microbial Rev 1993; 6; 428-42. PMCID: PMC358296.

7. Fridkin SK, Steward CD, Edward JR. Surveillance of antimicrobial use and antimicrobial resistance in united states hospitals:project ICARE phase 2 .Clin infect Dis. 1999; 29(2): 245-52.

8. Sahm DF, Marsilino MK, Piazza G. Antimicrobial resistance in key blood steam bacterial isolates: electronic surveillance with the surveillance network database- USA.Clin infect Dis. 1999; 29(2): 259-63. bacterial species and consequently better choice of treatment.

\section{ACKNOWLEDGEMENTS}

The authors would like to thank the Department of Research and Technology, Mazandaran University of Medical Sciences for their support and cooperation.

\section{CONFLICT OF INTEREST}

The authors declare no conflicts of interest regarding this manuscript.

9. Fraser VJ, Jones M, DunkelJ. Candidemia in a tertiary care hospital: epidemiology risk factors and predictors of mortality. Clin infect Dis.1992; 15(3): 414-21.

10. Husni RN, Goldstein LS, Arroliga AC, Hall GS, Fatica C, Stoller JK. Risk factors for an outbreak of multi-drug-resistance acinetobacter nosocomial pneumonia among intonated patients. Chest. 1999; 115(5): 1378-82.

11. Baron EJ, Finegold SM. Bailey \& Scott's diagnostic microbiology. $8^{\text {th }}$ ed. USA

; Mosby Co. 2008.

12. Karlowsky J A, Jones E, Deborah C, Dragil,C, Daniel F. Prevalence and antimicrobial susceptibilities of bacteria isolated from blood cultures of hospitalized patients in the united states. Ann $\begin{array}{lll}\text { ClinMicrobiolAntimicrob. } 2004 ; & 3:\end{array}$ doi: 10.1186/1476-0711-3-7.

13. Hsueh PR, Chen MI, Sun CC, Chen WH, Pan HJ, et al. Antimicrobial drug resistance in pathogens causing nosocomial infections at a university hospital in Taiwan1981-1999. Emerging infectious disease. 2002; 8(1): 451-459.

14. Arda B, Siphahi OR, Yamazhan T, Tasbakan M, Pullukch H, Tunger A, et al. Short term effect of antibiotic control policy on the usage patterns and cost of antimicrobials, mortality, nosocomial infection rates and antibacterial resistance. Journal of infection. 2007; 155(1): 41-48. 